THE time for the trial of machines for separating the fibres of the Rhea plant which are to be sent in by competition for the Indian Government prize of $5,000 l$, has been postponed till April 1872 . It is requested that notice of intention to compete be given before May of this year. Arrangements have been macle for supplying some of the plant to intending competitors.

\section{THE FIRST GERMAN NORTH POLE EXPEDITION}

$\triangle$ NUMBER of Petermann's" Mittheilungen" published in January 1871 , consists of an account of the first German North Pole Expedition by Captain Koldewy and Dr. A. Petermann. The vessel in which this expedition was undertaken was the Germania, a cutter of only eighty tons burden. Twelve persons sailed in her, Captain Koldewey, the commander of the party and joint author of the present memoir, R. Hildebrant, chief mate, and ten sailors. They started from Bergen May 24, 1868, the Swedish expedition sailing about the same time in a steamer. The voyage extended over four months. Dr. Petermann considers that the only practicable routes to the North Pole are either through Behring's Straits or the $s^{f}$ a between Greenland and Spitzbergen. The latter was attempted by the Expedition.

The year turned out to be a most unfavourable one, the sea being more than usually obstructed with ice. After vain'y attempting to reach the east coast of Greenland, the Germmia crossed over to Spitzbergen, but was stopped by pack-ice. Greenland was again visited with a like result; but on a second trial of the Spitzbergen route a fortunate break in the ice occurred, and on September 14 , lat. $81^{\circ} 5$ was reached, this being the highest point ever yet attained by a ship, although with sledges $82^{\circ} 45$ was reached by Parry in I $\$ 27$. The east coast of Spirzbergen was visited by means of the straits (Hinlopen Strasse) which seprate the smaller northern portion of this group of islands from the larger southern portion. Here a new island was discovered, and the surrounding coast-line mapped. Dr. Petermann names the island William Island, and the straits which separate it from the mainland Bismark Straits; we also find on the map Augusta Bay and Cape Moltke. Dr. Petermann rejoices greatly that the Germans have thus at last left their mark on the map. He says that it has been very trying to him to have seen for the last thirty-two years in maps of all parts of the world containing new geographical discoveries no names but "Victoria," "Wellington," "Smith," "Jones," \&c. Captain Koldewey describes the glaciers of Spitzbergen as differing from those of Switzerland in the following points:- They for the most part stretch right down into the sea, where they end in a perpendicular wall. The upper surface is somewhat polished and free from all roughness and steep ice blocks. Moreover in the glaciers examined at Augusta Bay and William Island there are no crevasses. Moraines are present, those of the great glacier in Augusta Bay consisting of limestone and basalt. The actual scientific results of the expedition are very small, owing to the badness of the weather. Some fragmentary monthly isothermals of sea temperature have been constructed by Dr. Petermann from the observations made during the voyage, and are marked on the two maps which accompany the memoir. Captain Koldewey considers that the route by the East coast of Greenland is the one which should be attempted by future exped:tions. The route north of Spitzbergen is impracticable, because a branch of the Gulf Stream here meets directly the cold polar current, and a barrier of ice is the result. For further exploration he advises the employment of a schooner rigged vessel of from 150 to 202 tons, with auxiliary steam power.

\section{REPORT ON DEEP-SEA RESEARCHES}

Carried on during the months of 7 ully, Aurus!, and Sepiember, 1870 , in H.M. Surveying Ship "Porcupine."

By W. B. Carpenter, M.D., F.R.S., and J. Gwyn JEFFREY, F.R.S.

(Concluded from p. 417.)

$W^{E}$ commenced our observations on the morning of Oct. $I$ at the point of greatest depth (Station 65). The temperature of the surface at 6 A.M. was only $63^{\circ}$, which was at least eight degrees Iower than the average temperature at that hour within the Mediterranean. The bottom temperature at 198 fathoms was $54^{\circ} .5$; and the specific gravity of the bottom water was $1028 \cdot 2$. The coincidence both in temperature and specific gravity with the bottom-water at Station 64 was thris very close. The place of the ship having been determined by angles taken with the shore, the rate of the surface-movement was tested as on former occasions; and was found to be $1 \cdot 277$ mile per hour, its direction being E. $\frac{1}{2}$ S. The "current drag" was then sunk to 150 fathoms, - the greatest depth at which it was thought safe to use it; and the boat from which it was suspended moved $E$. $\frac{3}{4} N$. at the rate of 0.840 mile per hour. This observation indicated a very considerable retardation in the rate of $i n$-flow; but gave no evidence of an out-flow. It did not, however, negative the inference deducible from the temperature, and still more from the specific gravity of the water beneath, that an out-flow takes place in that lowest stratum which we could not test by the "current drag."

We then steamed across the deep channel towards the Spanish side; and passing a bank of 45 fathoms which rises near its middle, we sounded again at Station 66, about six miles to the northward of Station 65. The surface-temperature at 9 A.M. was here found to have risen to $69^{\circ}$; and since not more than half this increase could be attributed, according to our experience elsewhere, to the increase of direct solar radiation at this period of the clay, the cause of the additional elevation has to be sought elsewhere. The length of sounding-line run out was 147 fathoms; but on attempting to reel $\mathrm{jt}$ in, the lead was found to have fixed itself between rocks; and all Capt. Calver's skill in the management of his ship proved inadequate to free it. As we were thus anchored by our sounding-line, it was requisite to set ourselves free, by putting a breaking strain upon it; and we thrs lost, with the lead, one of our water-bottles, and a pair of thermometers, one of which was specially valued by us as having been used thronghout the Porcupine Expedition of 1869 , in which the temperature soundings had proved of peculiar importance. The "current-drag" was here let down to Ioo fathoms ; and the boat from which it was suspended moved along in the direction of the surface-current, and at the rate of 1.280 mile per hour, which was alm:st precisely that of the surfacecurrent in the previous observation.

Deeming it important to obtain the temperature and specific gravity of the bottom-water on the Spanish side of the deeper portion of the channel, we slightly shifted our ground, and again let down nur lead, with thermometers and water-bottle, at Station 67 , where the depth proved to be 188 fathoms. On beginning to reel in the line, we found the lead to have anchored as before, and for some time feared that we should sustain a second loss of the water-bottle and thermometers attached to it. The means taken by Captain Calver for its extrication, however, proved on this occasion successful; and we had the satisfaction of seeing the whole apparatus safely brought up, - - the lead bearing evident marks of having been jammed between rocks and then violently strained. The temperature of the bottom proved to be $55^{\circ} \cdot 3$, that of the surface being $73^{\circ}$; and the specific gravity of the bottom-water was $1028 \cdot 1$, that of the surface being 1026.8. Here again, therefore, the evidence afforded by the tem. perature and specific gravity of the bottom-water was conclusive as to its Mediterranean character. Its density corresponded rather with that of the bottom-water, than with that of the inte:mediate stratum, at the opposite end of the Strait ; but the more rapid westerly motion of the latter would seem to indicate that the water which here flows over the "ridge" is derived from it, rather than from the deeper layer, and that its diminution in density is due to the dilution it sustains in its course. In either case, the denser Mediterranean water discharged by this undercurrent must flow up-hill; but the incline is so gradual that a vexy small force, if constantly sustained, would suffice to produce the elevation needed to carry it over the ridge. 
Whilst we were prosecuting these inquiries, our attention was attracted by the long chains of aggregate salpæ which were floating close to the ship near the surface of the very calm sea. We were able to collect four or five different species of these, and to submit them during life to microscopic examination. The reversal of the direction of the circulation took place in all at more regular intervals than we have usually found to be the case in the compound ascidians; and we were able to distinguish an unmistakable rudimentary eye, which had not, we believe, been previously noticed. We hope to be able hereafter, by the detailed study of these specimens, to make some additions to the knowledge previously acquired of this very interesting group. As the nature of the bottom put it out of the question to attempt to dredge on this ridge, our only means of investigating its zoology lay in the use of the "hempen tangles." A "sweep" taken with these bronght up a few echinoderms and polyzoa of no special interest.

We now took our final leave of the Mediterranean basin with mingled feelings of disappointment and satisfaction. The zoological results of our cruise had been by no means equal to our expectations ; but, on the other hand, we could console ourselves with the belief that our determination of the peculiar physical conditions of this great inland sea, and in particular our elucidation of the mystery of the Gibraltar current, would be fairly regarded as a success. And we venture to think that this will be admitted by such as may follow us through the discussion of general resulis, to which we shall presently proceed.

As Captain Calver considered himself bound not to make any unnecessary delay in returning homewards, and to take every advantage of the continuance of the fair weather and favourable breeze which we enjoyed during nearly the whole remainder of our voyage, we were reluctantly compelled to give up the idea of prosecuting any further researches in the Deep Sea ; and devoted ourselves to the examination of the specimens previously collected, and to the correlation of our temperature and other results, - specially directing our attention, however, to the surfacetemperature of the embouchure of the Strait, with the view of ascertaining whether a sudden fall would be observable on quitting it, corresponding to the rise which had been noticed on the outward voyage on entering it. This change proved to be very decided. As we kept along the southern coast of Portugal lowards (ape St. Vincent, the surface-temperature averaged $73^{\circ} \cdot 5$. At 6 P.M. we were turning the corner of the Cape, and found the surface-temperature $72^{\circ} \cdot 5$. And at 8 P.M., when we were fairly in the Atlantic, we found that the surfacetemperature had fallen to $69^{\circ}$, thus showing a difference of $4^{\circ} 5$. On the following day, when we were off Lisbon, the surfacetemperature was $69^{\circ} \cdot 5$; and it gradually diminished as we proceeded northwards from that point. Although the season of the year led us to expect a rough passage across the Bay of Biscay, the weather continued remarkably fine until we reached the "Chops of the Channel," where we fell in with rather a fresh breeze ; this did not interfere, however, with our anchoring at Cowes on the afternoon of the next day (October 8th), after an absence of just two months, during which a greater number of most important public events had occurred than had ever before beèn crowded within so short a period.

General Oceanic Circulation. - The difference as to level and density between two bodies of sea-water, which produces the vertical circulation in the Strait of Gibraltar and the Baltic Sound, may be brought about otherwise than by the excess of evaporation which maintains it in the one case, or by the continual dilution with fresh water which maintains it in the other. It may be easily shown that a constant and decided difference of temperature must have exactly the same effect. Let the Mediterranean basin be supposed to be filled with water of the same density as that of the Atlantic and up to the same level; and to be then cooled down below the freezing-point of fresh water by the withdrawal of solar heat, whilst the surface of the Atlantic continues to be heated as at present by the almost tropical sunshine of the Gibraltar summer. The cooling of the Mediterranean column, reducing its bulk without any diminution of weight, would at the same time lower its level and increase its density. An in-draught of Atlantic water must take place through the Strait to restore that level; but this in-draught would augment the weight of the column, giving it an excess above that of the column at the other end of the Strait; and to restore the equilibrium a portion of its deeper water must be forced out as an under-current towards the Atlantic, thus again reducing the surface-level of the Mediterranean. Now, so long as the warm
Atlantic water which comes in to maintain that level is in its turn subjected to the same cooling, with consequent lowering of level and increase of density, so long would the vertical pressures of the two columns, which would be speedily restored to equilibrium if both basins were subjected to the same heat or the same cold, remain in a constant state of inequality; and so long, therefore, must this vertical circulation continue.

Now, the case thus put hypothetically has a real existence. For the Mediterranean, cooled down by the withdrawal of solar heat, let us substitute the Polar basin, and for the Atlantic, the Equatorial Ucean. The antagonistic conditions of temperature being constantly sustained, a constant interchange between polar and equatorial waters through the seas of the Temperate Zone must be the result. The reduction in the temperature of the Polar column must diminish its height whilst augmenting its density; and thus a flow of the upper stratum of equatorial water must take place towards the lpoles to maintain the level thus lowered. But when the column has been thus restored to an equality of height, it will possess such an excess of weight that its downward pressure must force out a portion of its deeper water; and thus an underflow of ice-colà water will be occasioned from the polar towards the equatorial areas.

The agency of polar cold will be exerted, not merely in reducing the bulk of the water exposed to it, and thereby at the same time lowering its level and increasing its density, but also in imparting a downuard monement to each new surface-stratum as its temperature is reduced, whereby a continual in-draught will be occasioned from the warmer surface-stratum around. For the water thus newly brought under the same same cooling influence will descend in its turn; and thus, as the lowest stratum will be continually flowing off, a constant motion from above downwards will continue to take place in the entire column, so long as a fresh stratum is continually being exposed to the influence of surface-cold.

On the other hand, the agency of equatorial heat, though directly operating on only a thin film of surface-water, will gradually purnp-up (so to speak) the polar water which has reached its area by creeping along the deepest parts of the intermediate oceanic basins. For since, as already shown, an indraught of the upper stratum surrounding the polar basin must be continually going on, the place of the water thus removed must be supplied by water drawn from a still greater distance; and thus the movement will be proparated backwards, until it affects the upper stratum of the equatorial basin itself, which will flow off pole-wards, bearing with it a large measure of heat. The cold and dense polar water, as it flows in at the bottom of the equatorial column, will not directly take the place of that which has been draughted off from the surface; but this place will be filled by the rising of the whole superincumbent column, which, being warmer, is also lighter than the cold stratum beneath. Every new arrival from the poles will take its place below that which precedes it, since its temperature will have been less affected by contact with the warmer water above it. In this way an ascending movement will be imparted to the whole equatorial column, and in due course every portion of it will come under the influence of the surface-heat of the sun. This heat will of course raise the level of the equatorial column, without augmenting its absolute weight; and will thus add to the tendency of its surface-stratum to flow towards the lowered level of the polar area. But as the super-heating extends but a short way down, and as the temperature of the water beneath, down to the "stratum of intermixture," is very moderate, whilst the water below that stratum is almost as cold as that of the polarbasin, it is evidently in the latter that the force which maintains this vertical circulation chiefly originates.

Here, then, we have a vera causa for a general oceanic circulation, which, being sustained only by the unequal distribution of solar heat, will be entirely independent of any peculiar distribution of land and water, provided always that this does not prevent the free communication between the polar and equatorial oceanic areas, at their depths as well as at their surface. That this agency has been so little recognised by physical geographers, we can only attribute to the prevalence of the erroneous idea of the uniform deep-water temperature of $39^{\circ}$, of which the temperature-observations made in our expeditions of 1868 and 1869 have shown the fallacy. Until it is clearly apprehended that sea-water becomes more and more dense as its temperature is reduced, and that it consequently continues to sink until it freezes, the immense motor power of polar cold cannot be apprehended. But when once this has been clearly recognised, it is seen that 
the application of cold at the surface is, in the case of sea-water, precisely equivalent as a moving force to the application of heat at the bottom, the motor power of which is universally admitted, -being practically utilised, in keeping up the circulation through the hot water warming apparatus now in general use.* The movement thus maintained would not, on the hypothesis, be a rapid one, but a gradual creeping flow; since the absence of limit would prevent the power which sustains it from acting as an accelerating force, as it would do if the equatorial and polar areas were connected only by a narrow channel, like the Atlantic Ocean and the Mediterranean Sea.

That the vertical circulation here advocated on a priorigrounds, actually takes place in any mass of salt water of which one part is exposed to surface-cold and another to surface-heat, is capable of ready experimental proof:- - Let a long narrow trough with glass sides be filled with salt water; and let heat be applied at one end (the equatorial) by means of a thick har of metal lairl along the surface, with a prolongation carried over the end of the trough into the flame of a spirit-lamp; whilst cold is applied at the other (the polar) by means of a freezing-mixture contained in a metallic box made to lie upon the surface, or (more simply) by means of a piece of ice wedged in between the sides of the trough. A circulation will immediately commence in the direction indicated by the theory; as may be readily shown by introducing some blue colouring liquid at the polar surface, and some red liquid at the equatorial surface. The blue liquid, as it is cooled, at once descends to the bottom, then travels slowly along until it reaches the equatorial end of the trough, then gradually rises towards the heated bar, and thence creeps along the surface back to the polar end. The red liquid first creeps along the surface towards the polar end; and then travels through exactly the same course as the blue had previously done. $\dagger$

That such a vertical circulation really takes place in oceanic water, and that its influence in moderating the excessive cold of the polar areas and the excessive heat of the equatorial region is far more important than that of any surface-currents, seems to us a legitimate deduction from the facts stated in the Report of the "Porcupine" Expedition for I 869 . For, on the one hand, it was shown that there is a general diffusion of an almost glacial temperature on the bottom of the deep ocean-basins, at depths exceeding rooo fathoms, occupied by polar water, more or less diluted by admixture according to the length of the course it has had to travei ; whilst between this stratum and that other stratum of warmer water which (on the hypothesis) is slowly moving pole-wards, there is a "stratum of intermixture," in which there is such a rapid change of temperature as might be expected from the relation of the upper and lower masses of water. This "stratum of intermixture" showed itself in a most marked manner in the Atlantic temperature-observations of the present expedition; the descent of the thermometer, which had been very slow with increase of depth between 100 and 800 fathoms, becoming suddenly augmented in rate; so that between 800 and 1000 fathoms it fell nine degrees, namely, from $49^{\circ} 3$ to $40^{\circ} \cdot 3$.

On the other hand, it was shown in the previous report that there is evidence of the slow pole-ward movement of a great upper stratum of oceanic water, carrying with it a warm temperature; which movement cannot be attributed to any such local influences as those which produce the Gulf-stream or any other currents put in motion by surfaceaction. Of such a movement, it was contended, we have a marked example in that north-easterly flow which conveys the warmth of southern latitudes to the west of Ireland and Scotland, the Orkney, Shetland, and Faroe islands, Iceland, Spitzbergen, and the polar basin generally. This flow, of whose existence conclusive evidence is derived from observations of the temperature of these regions, is commonly regarded as a prolongation of the Gulf-stream; and this view is maintained not only by Dr.

* The only scientific writer who has even approached what appears to us the truth on this point, is Captain Maury, whohas put forward the doctrine of a general interchange between the equator and the poles, resulting from a difference of specific gravity caused inter alia by difference of temporature. But. as Mr. Croll remarks, "aithough Captain Maury has expounded his views on the cause of ocean currents at great length in the various editions of his work, yet it is somewhat difficult to discover what they really are. This arises from the general confused and sometimes contradicrory nature of his hydrodynamical conceptions." See Mr. Croli's Paper " ") the Physical Cause of Ocean Currents," in the "Philosoptical Magazine" for Uctober, I870.

$\uparrow$ This experiment has been exhibited, by the kindness of Prof. Odling, at the Royal Institution, and at the Royal Geographical Society.
Petermann, * who has recently collected and digested these observations with the greatest care, but also by Prof. Wyville Thom. son, + as well as by Mr. Croll. $\neq$ Having elsewhere fully stated our objections to this doctrine, and discussed the validity of the arguments atduced in support of it, $\S$ we shall here only record the conclusions which a careful examination of the present state of our knowledge of the subject has led us to form :-

I. That there is no evidence, either from the surface-temperature of the sea, or from the temperaturs of sea-board stations along the western coast of Southern Europe, that the climate of that region is ameliorated by a flow of ocean-water having a tempera. ture higher than that of the latitude: the surface-temperature of the Mediterranean Sea, which is virtually excluded from all oceanic circulation, being higher than that of the eastern margin of the Atlantic in corresponding latitudes; and the climate of sea-board stations on the Mediterranean being warmer than that of stations corresponding to them in latitude on the Atlantic coast -and this not merely in summer, but also in winter. This oceanic region may therefore be designated the neutral area.

II. That the evidence of climatic amelioration increases in proportion as we pass northwards from the neutral area; becoming very decided at the Orkney, Shetland, and Faroe islands. But that, as was shown by the Porcupine temperature-soundings of 1869 , the flow of warm water which produces this amelioration extends to a depth of at least 700 fathoms.

III. That this deep stratum of water can be shown, by the correspondence in the rate of its diminution of temperature with depth, to be derived from the neutral area to the south-west; where, as is shown by the Porcuspine temperature-soundings of 1870 , it is separated by a distinct "stratum of intermixture" from the deeper stratum that carries polar waters towards the equator.

IV. That the slow north-easterly movement of such a mass of water cannot, on any known hydrodynamical principles, be attributed to propulsive power derived from the Gulf-stream; the last distinctly traced edge of which is reduced to a stratum certainly not exceeding 50 fathoms in depth, and not improbably less.

$V$. That on the other hand, this slow pole-ward movement of the upper layer of the North Atlantic, down to the "stratum of intermixture," is exactly what might be expected to take place as the complement of the flow of glacial water from the polar to the equatorial area; the two movements constituting a general vertical oceanic circulation.

VI. That there is a strong probability that the quantity of water discharged by the Gulf-stream has been greatly over-estimated, in consequence of the rate of the surface-current having been assumed as the rate of movement through the whole sectional area, which is contrary to all analogy; whilst there is also a strong probability that there is a reverse undercurrent of cold water through the narrows, derived from the polar current, that is distincly traceable nearly to its mouth. The upper stratum of this southerly current comes to the surface between the Gulf-stream and the coast of the United States; whilst its deeper and colder stratum underlies the Gulf-stream itself.

VII. That there is a strong probability that the quantity of heat carried off by the water of the Gulf-stream has been greatly over-estimated; the temperature-soundings taken during the cruise of the Porcupine in the Mediterranean having shown that the very high temperature of the surface extends but a little way down; whilst the temperature observations in the Atlantic show that the descent into a cold stratum beneath may be very rapid. Hence the average of $65^{\circ}$ assumed by Mr. Croll on the basis of observations made at considerable intervals of depth, is altogether unreliable.

ViII. That the most recent and trustworthy observations indicate that the edge of the Gulf-stream to the north-east of the banks of Newfoundland is so thinned out and broken up by interdigitation with polar currents, that its existence as a cont.

* Geographische Mittheilungen, 2870 , p. 20I.

+ Lecture "On Deep-sea Climat $-s$," in NATURE, July 28,1870 $\ddagger$ Memoir "On the rhysical Cause of Ucean Currents," in "Phil. Mag., Oct. 1870

\& Proceedings of the Royal Geographical Society, for Jan, 9, I87x. If That there is a siow southerly movement of Arcic water teneath the Culf-stream, is indicated by the fact that icebergs have been seen moving sourhward in direct opposition to its surface-flow; their deeply-immersed portions presenting a larger surface to the lower stratum than their upper p.rt does to the more superficial layer, as in the case of our " current-drag." And similar evidence is affurd rd by the southward drift of the buoy which was attached to the Atlantic Cable of 1865 , bat which broke away from it, apparently cartying with it a great length of the wire rope by which it had been attached. 
tinutous current beyond that region cannot be proved by observations, either of temperature or movement.

IX. That the Gulf-stream and other local currents put in motion by the trade-winds or other influences acting on the surface only, will have as their complement in a horizontal circulation return surface currents; and that the horizontal circulation of which the Atlantic Equatorial Current and the Gulf-stream constitute the first part is completed-so far as the Northern Hemisphere is concerned-partly by the direct return of one large section of the Gulf-stream into the Equatorial Current, and as to the other section, by the superficial polar currents which make their way southwards, the principal of them even reaching the commencement of the Gulf-stream.

In conclusion it may be added that the doctrine of a general vertical oceanic circulation is in remarkable accordance with the fact now placed beyond doubt by the concurrent evidence of a great number of observations, that whilst the density of oceanic water, which is lowest in the Polar area, progressively increases as we approach the Tropics, it again shows a decided reduction in the intertropical area. It has been thought that an explanation of this fact is to be found in the large amount of rainfall and of inflow of fresh water from great rivers in the intertropical region; but it is to be remembered that the surface evaporation also is there the most excessive, so that some more satisfactory account of the fact seems requisite. Such an explanation is afforded by the doctrine here advocated; the Polar water which flows towards the Equator along the bottom of the ocean basins, being there pumped up and brought to the surface.* And it is not a little confirmatory of the views advanced in this Report that in a recent elaborate discussion of the facts relating to the comparative density of oceanic water on different parts of the earth's surface, the doctrine of a general vertical circulation is advocated as affording the only feasible rationale of them. $\downarrow$.

\section{SCIENTIFIC SERIALS}

THE Zettschrift fur Ethnologie (I870 Heft III. and IV contains the following notices:-Orton's "Andes and the Amazon." - Waring's "Stone Monuments, Tumuli, \&c.," "Manuscrit Troano" giving an account of the MS. in question, which is written in the Maya language; the reviewer calls this "surely the wildest production that ever saw the light with the sanction of an Imperial Government," though he admits that still wilder productions are published in his own country, now also under "Imperial government."-Benfey's "Gesch. de Sprachwissenschaft" is highly praised.-Burgen's "Temples of Satrunjaya," with forty-five photographs. Hamy's "Paléontologie Humaine."

THE last part of the "Neues Jahrbuch fuir Mineralogie, Geologie," \&c., published 187 I, contains the following papers:R. D. M. Verbeek on the Nummulites of the Borneo Rocks, with three plates illustrating new species, \&c., one species, $N$. Biaritzensis, is also found in these beds, and extends through all the nummulitic formation from the Pyrenees to Borneo. $\mathrm{He}$ believes that this formation extends to Java and most of the islands of the East Indian Archipelago, but hitherto this formation has not been recognised. $\neq-D r$. R. Lincke on the Buntersandstein in Thüringen, which is the commencement of an elaborate monograph on these beds. - Dr. Allred Stelzner on Quartz and Allied Minerals. - Adolph Pichler, Additions to the Mineralogy of the Tyrol; and, by the same author, Additions to the Palæontology of the Tyrol, and the usual mineralogical, geological, and palceontological notices.

Of the Transactions of the Natural History Society of Rhenish Prussia and Westphalia, including also the reports of the Society of Natural History and Medicine of the Lower Rhine, we have received the twenty-sixth volume, containing an account of the doings of the respective societies in the year 1869 . The papers published by the first-mentioned society are well known to naturalists, and often of very great value. In the present volume we find the following :-- "Contributions to the Rhenish Flora,"

* That water of a lozver should thus underlie water of a higher degree of salinity in travelling from the Pole to the Equator, is not difficult to account for, when the relative temperatures of the two strata are borne in mind. + Densité, Salière, et Courants de l'Ocet Annales Hydrographiques, 1868, p. 620

It is not out of place to mention here that Baron Reichtofen has quite recently found this nummulitic formation in China; it is described Silliman's Foumnl for February 187x. It has been found also in Japan. by Dr. P. Wirtzen, including a discussion of the species of dogroses, with the description of a so-called new species, Rosa exilis, a notice of Asplenizum Heufleri, the description of a new plantain from Saarbruck, Plantago Winteri, a notice of the various forms of Rubus tomentosus, and of anomalies in other species of Rubus, and notices on the geographical distribution of certain plants; also, by the same author, a supplement to his manual of "The Flora of Rhenish Prussia; a paper "On the Height of the Water of the Rhine at Cologne from 181 I-1867," by M. H. von Dechen ; the continuation of Kaltenbach's valuable memoir on the German Phytophagous insects, in which the species feeding upon each species of plant are noticed, the plants being arranged. in the alphabetical order of their botanical names, now reaching to the end of the letter S. ; a contribution to the knowledge of the cryptogamous flora of the Saar district, by M. F. Winter, containing notices of Equisetaceæ, Lycopodiaceæ, and Ferns; and a paper, illustrated with three plates, "On the Fossil Echino. dermata of North Germany," by Dr. C. Schliiter. In the last* mentioned paper, the author notices the described species of Jurassic and Cretaceous Echinoderms found in North Germany, and describes several new forms. The repcrts of the second society mentioned, which holds its meetings in Bonn, include an immense number of short notices of communications on almost a'l branches of science, but especially on Natural History and Chemistry ; many of them are of considerable interest.

IN the March number of the foumal of Anthropology there is a careful anatomical description of the body of a negro by Dr. Kopennéki. Detailed measurements are added, together with the weights of the principal organs, and the diameter of more than twenty of the nerves. A remarkable feature in the case was the state of atrophy in which the supra-renal bodies were found; and if, in the absence of other fatal lesions, this may be assumed as the cause of death, there is here recorded a case of Addison's disease occurring in a negro. In the same journal is a translation of a review by Ruitimeyer of Prof. Bischoff's work on the skulls of the anthropoid apes, in which both the text and the atlas of plates which accompanies it are severely criticised. Both the original pamphlet and the review have, however, lost much of the interest they possessed at the times of the publication, I864 and 1868 respectively.

\section{SOCIETIES AND ACADEMIES \\ LONDON}

Royal Society, March 30.-- "Contributions to the History of Orcin.-No. I. Nitro-substitution Compounds of the Orcins." By John Stenhouse, LL.D., F.R.S. The action of nitric acid upon orcin has been studied by several chemists, but with comparatively negative results. Schunck in this manner obtained a red resinous substance, which, by further treatment with the acid, was oxidised with oxalic acid; and in 1864 De Luynes found that orcin dissolved in cooled fuming nitric acid without evolution of nitrous fumes, and that the addition of water precipitated a red colouring matter; the long-continued action of the vapour of fuming nitric acid on powdered orcin likewise produced a red dye apparently identical with the above. These, however, are resinous uncrystallisable substances. Although under ordinary circumstances only resinous products are obtained by treating orcin with nitric acid, yet, when colourless orcin in fine powder is gradually added to strong nitric acid, cuoled by a freezing mixture, it dissolves with a pale brown coloration, but without the slightest evolution of nitrous fumes. If this solution be now slowly dropped into concentrated sulphuric acid, cooled to $-10^{\circ} \mathrm{C}$., the mixture becomes yellow and pasty, from the formation of nitro-orcin, which is but slightly soluble in sulphuric acid. When this is poured into a considerable quantity of cold water, the nitro-body separates as a bright yellow crystalline powder, quite free from any admixture of resin. The crude nitro-orcin was collected, washed with a little cold water, and purified by one or two crystallisations from boiling water ( 40 parts). It was thus obtained in large yellow needles, which are readily soluble in hot water and but slightly in the cold; the addition of a strong acid precipitates almost the whole of the nitro-orcin from its cold aqueous solution. It is soluble in alcohol, very soluble in hot benzol, and crystallises out in great part on cooling ; it is less soluble in ether, and but moderately so in bisulphide of carbon. It dyes the skin yellow, like picric acid, but is tasteless. It volatilises slightly at $100^{\circ} \mathrm{C}$., melts at $162^{\circ} \mathrm{C}$, and decomposes with slight explosion imme- 